\title{
Fruit abscission pattern of 'Valencia' orange with canopy shaker system
}

Fernando Aragón-Rodríguez, Sergio Castro-García*, Rafael Rubén Sola-Guirado, Jesús A. GilRibes

Department of Rural Engineering, E.T.S.I. Agronomos y Montes, University of Cordoba, Campus de Rabanales, Ctra. Nacional IV Km 396, Cordoba, Spain

* corresponding author, scastro@uco.es

\section{GRAPHICAL ABSTRACT}

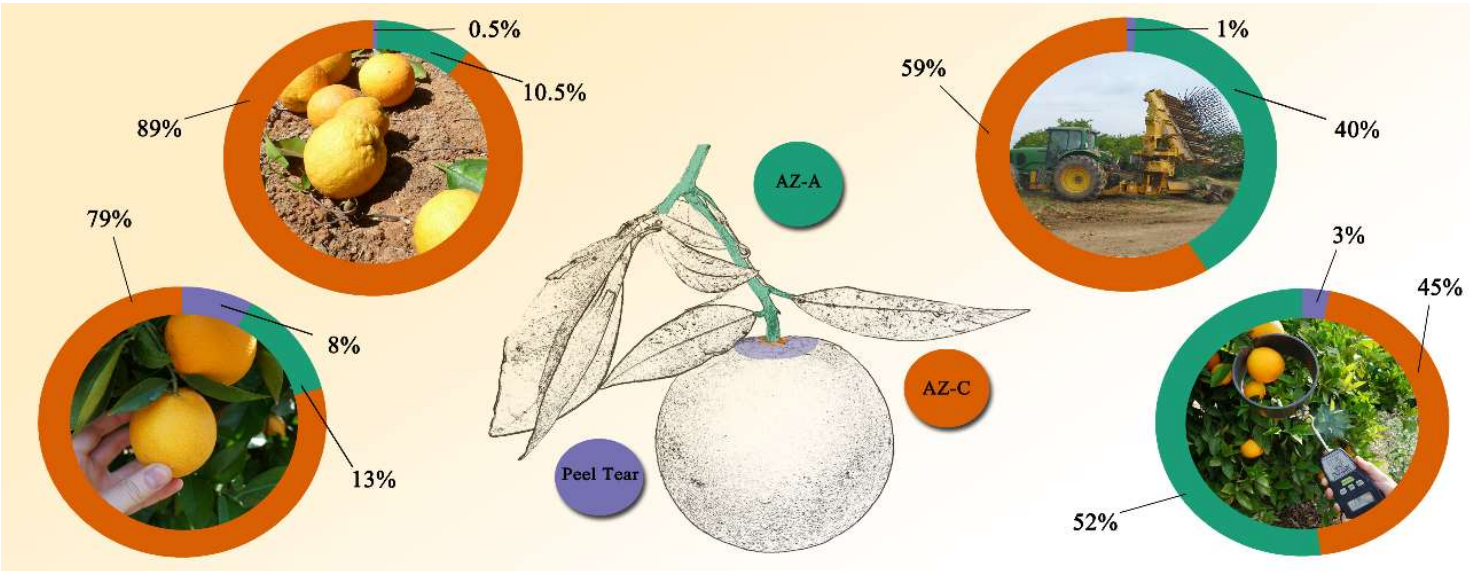

\section{ABSTRACT}

Fruit detachment can occur due to natural causes or be mechanically performed by a combination of mechanical stresses that cause tissue breakage in the plant. Forced abscission should not coincide with natural abscission zones (AZ). Abscission zones are very important in citrus harvesting both in terms of the destination market and of the possible damage caused to the tree or fruit. The objective of this study is to determine the abscission pattern of sweet oranges with a canopy shaker and compare it with other detachment systems. Five plots of Valencia oranges were tested during the 2017 and 2018 harvesting seasons, using a commercial tractor-drawn canopy shaker. The diameter, weight and breakage type were evaluated in the cases of natural fall, snap method, mechanical harvesting with canopy shaker, and pull test. Breakage type AZ-C predominated in natural fall (89.0\%) and the snap method (79.5\%). Similarly, AZ-A predominated for the canopy shaker (58.8\%) and pull test (45.3\%). Mechanical action on the fruit produced peel tear by breaking the flavedo, which reached highest frequency in the snap method (7.6\%). Peel tear breakage required a mean fruit detachment force value of 99.3 $\mathrm{N}$, higher than the average abscission values for AZ-C $(88.7 \mathrm{~N})$ and AZ-A $(66.6 \mathrm{~N})$. The fruit that remained on the tree after canopy shaker harvesting showed lower mean values of fruit detachment force $(16.3 \%)$ than the pre-harvest fruit. The frequency of fruit with calyx with the canopy shaker and snap methods was similar, with a mean value of $36 \%$.

\section{INTRODUCTION}

Fruit detachment can be produced by natural causes or by the action of an external agent. The natural process of fruit abscission is a strategy of the plant to discard ripe or damaged fruit, as 
well as to disperse seeds. Citrus harvesting takes place during the ripening phase of the fruit, before natural fall occurs (Ladaniya, 2008). Different manual and mechanised methods are employed to detach the fruit from the tree.

For the fresh market, the most commonly used method is manual clipping: the fruit is cut by its peduncle and maintaining its calyx. When fruit is destined for industry, the snap manual method is one of the most frequent: the fruit is detached by twisting the fruit stem and pulling it manually (Ladaniya, 2008). Currently, mechanical harvesting systems are used for fruit destined for processing, mainly employing trunk shakers (Torregrosa et al., 2009) and canopy shakers (Peterson, 1998). Both technologies perform a forced vibration, which is transmitted to the fruit and causes fruit detachment (Castro-Garcia et al., 2017). Canopy shakers are the most developed and used commercial systems, allowing continuous work and reaching high fruit detachment efficiency values (>90\%) if the orchard and the operator are trained (Roka et al., 2014).

In all these methods, fruit detachment force (FDF), together with other parameters such as firmness and soluble solids, are parameters of great interest used to evaluate the abscission agents, plant growth regulators or nutrition and harvest planning. FDF is determined with another harvesting method, the pull test. Although this is a method that serves as a predictor of the efficiency of mechanical harvesting, the way in which fruit removal occurs mechanically is slightly different to how the pull test method is performed (Liu et al., 2017). It would therefore be advisable to study in greater depth the differences between FDF with the pull test and with these harvesting methods.

The choice of a harvesting method is conditioned by factors such as the available technology, the orchard layout type, and the cost or availability of labour. However, the quality of the harvested fruit is one of the most important parameters and is highly related with the sector it is destined for. The fresh market requires undamaged fruit skin and fruit interior with an intact calyx, to conserve its organoleptic and antifungal properties. However, citrus fruit for industrial processing can tolerate certain types of external damage (Moreno et al., 2015).

Citrus fruits have two main natural abscission zones (AZ): AZ-A located between the peduncle and the branch, and AZ-C, located between the calyx and the fruit. AZ-A is predominant during immature fruitlets development. After this time, AZ-C becomes the predominant zone (Goren, 1993). However, when abscission is forced for harvesting, a combination of mechanical efforts are applied, normally to break some plant tissues. In this case, forced abscission zones may or may not coincide with natural $A Z$.

The way the forced abscission of fruit happens is important for the tree, for the fruit and for its subsequent management. The mechanical harvesting system employed can affect the following year's production when detached fruit maintains part of the branches. Roka et al. (2005) showed damage production reductions between $20 \%$ and $50 \%$ dependant on the regulation of mechanized harvesting. Fruit abscission with or without the calyx is basic for packed conservation and for the fresh market.

The objective of this work is to determine the abscission pattern of the sweet orange with mechanical harvesting using canopy shaker systems compared with other fruit detachment methods. Evaluation of the abscission pattern can contribute to the development of the machinery used for mechanized harvesting of this crop, to the development and management of products that favour abscission and to determining whether the harvested fruit can feasibly be destined for the fresh market or for industrial processing.

\section{MATERIAL AND METHODS}


Fruit abscission patterns where studied for the following detachment methods: natural fall, manual snap method, mechanical canopy shaker and manual pull test. The fruit evaluated from natural fall was collected from the ground during the harvesting periods and had no visible external damage. Fruit evaluated for the manual snap method was harvested by farm workers. Mechanical fruit harvesting was performed with a tractor-drawn continuous canopy shaker system (Ploeger Oxbo Group; Oxbo 3210, New York, USA.), with 288, 1.4 m-long rods working within a range of 1-1.25 $\mathrm{km} \mathrm{h}^{-1}$ of ground speed and vibrating from 4.5 to $5 \mathrm{~Hz}$ (Figure 1). The fruit evaluated with the manual pull test was detached by applying a continuous increasing tensile force on the fruit near the calyx in the main direction of the branch (Figure 2).

Tests were carried out in the south of Spain (Cordoba) on 5 plots of commercial sweet oranges (Citrus sinensis (L.) Osbeck cv. Valencia) (Figure 3) during the 2017 and 2018 harvesting seasons on four dates distributed throughout each harvesting campaign (Table 1), after flowering and before the natural fall of immature fruit. The trees were trained in a V-shape with three or more main branches, in a wide hedgerow for mechanical harvesting with a lateral canopy shaker. Table 1 shows the data of the fruit evaluated and the plots tested.

The fruit abscission pattern was evaluated for 2540 pieces of fruit (1034 and 1506 for seasons 2017 and 2018, respectively). The fruit tested showed an average weight of $182.4 \mathrm{~g}$, a juice percentage of $54.9 \%$, an equatorial diameter of $70.0 \mathrm{~mm}$, a soluble solids rate of $11.32^{\circ}$ Brix and an acidity of 0.83 titratable acid. Classification of the AZ was performed for each fruit the following groups (Figure 4):

- Peel tear: break with a portion of flavedo.

- AZ-C: break between peduncle and fruit, with floral disk. This group was divided into two categories: fruit with and fruit without calyx.

- AZ-A: break in another part of the stem. This group was divided into two categories: breakage in the peduncle or breakage in any part of the branch.

FDF was measured in the harvestable canopy area before mechanical harvesting, and after mechanical harvesting for random fruit remaining on the tree, using 1980 pieces of fruit with repetitions of $45+45$ fruits over the tests and repetitions.

\section{RESULTS}

Fruit presented a slight linear increase in average weight throughout the harvesting campaign for the two harvesting seasons and the five trial plots (2017 season: Pearson $=0.344, p<0.01, n$ $=777 ; 2018$ season: Pearson $=0.145, \mathrm{p}<0.01, \mathrm{n}=1217)$. In addition, there was a significant positive linear relation between fruit weight and equatorial diameter $\left(R^{2}=0.732, n=1993\right)$. The mean values of fruit weight and diameter did not show significant differences with regard to the detachment method used (ANOVA, $F=1.02, p>0.05, n=2540$ ).

Mean FDF values throughout the harvesting season showed high variability but no significant differences with regard to the harvesting period (ANOVA, $p>0.05$ ). In both harvesting seasons, as the harvesting date progressed there was a slight linear reduction of FDF values (2017 season: Pearson $=-0.138, \mathrm{p}<0.05, \mathrm{n}=276 ; 2018$ season: Pearson $=-0.186 \mathrm{p}<0.05, \mathrm{n}=173)$ and an increase in fruit diameter (2017 season: Pearson $=0.227, p<0.01, n=276 ; 2018$ season: Pearson $=0.229, \mathrm{p}<0.01, \mathrm{n}=173$ ) was determined.

Figure 5 shows abscission patterns according to fruit detachment method. Peel tear breakage was greater with the snap method $(7.6 \%)$ than with the canopy shaker $(1 \%)$ or natural fall $(0.4 \%)$ (Tukey post-hoc test, $p>0.05$ ). However, the abscission patterns of AZ-C and AZ-A showed an opposite tendency depending on the fruit detachment method used. AZ-C was higher in natural fall fruit $(89.0 \%)$ and with the snap method (79.5\%). These detachment methods showed significant differences in mean fruit values for AZ-C (Tukey post-hoc test, $p>0.05$ ) compared 
with the canopy shaker (58.8\%) and pull test (45.3\%). In contrast, AZ-A was higher in fruit with the pull test (51.8\%) and canopy shaker $(40.2 \%)$, and the mean value significantly decreased for the snap (12.9\%) and natural fall (10.6\%) methods (Tukey post-hoc test, $p>0.05)$. Using the snap method, there was an increase in the number of fruits with peel tear abscission (from 0.4 to 7.6\%) and AZ-A abscission (from 10.6 to $12.9 \%$ ) compared to natural fall. The canopy shaker increased the number of fruits with AZ-A abscission 3.1 times compared to the snap method.

The number of fruits with abscission in AZ-C with calyx was higher with the canopy shaker $(41.6 \%)$ and the snap methods $(30.2 \%)$ than with pull test $(15.5 \%)$ or natural fall $(7.3 \%)$ (Tukey post-hoc test, $p>0.05$ ). The number of fruits with abscission in AZ-A by the peduncle was very low, with $0.7 \%$ for natural fall, $0.9 \%$ for the snap method, $3.4 \%$ for the pull test and $6.1 \%$ for the canopy shaker.

The fruit showed significant differences in FDF for fruit detachment according to AZ (Figure 6, Before). A break by the flavedo required a mean FDF of $99.3 \mathrm{~N}$, higher than for an AZ-C break $(88.7 \mathrm{~N}$ ) and an AZ-A break (66.6 N) (Tukey post-hoc test, $\mathrm{p}>0.05)$. In fruit with AZ-C abscission, a linear regression was found between FDF and fruit diameter (Pearson=0.401, $p<0.01, n=991$ ): $33 \%$ of this fruit was detached with calyx, with higher significant FDF values $(94.0 \mathrm{~N})$ (t-Student, $t=7.087, p=0.000)$ than for fruit without calyx $(78.8 \mathrm{~N})$. A break by the peduncle in AZ-A required a higher FDF $(81.8 \mathrm{~N})$ than in the branch $(65.5 \mathrm{~N})$.

Fruit detached by pull test with abscission type peel tear show no significant differences (Student, $t=1,550, p>0.05$ ) before or after mechanical harvesting, with a mean value of $2.42 \%$. However, the use of a canopy shaker significantly increased the average amount of fruit with AZ-A abscission from 45 to $50 \%$ (Student $t, t=-2.05$, significance level $p<0.1, p=0.54, n=22$ ) and reduced the amount of fruit with abscission by AZ-C from 50 to $45 \%$ (Student $t, t=1734$, significance level $p<0.1, p=0.98, n=22$ ). Moreover, the fruit remaining on the tree after mechanical harvesting with AZ-C abscission had significantly lower (t Student, $t=7.63, p=0.000$, $\mathrm{n}=22)$ mean values of FDF $(73.6 \mathrm{~N})$ than the fruit with the same abscission before the machine $(87.9 \mathrm{~N})$. This reduction in the mean value of FDF was distributed in the same way between fruit that conserved the calyx or did not ( $t$ Student, $t=4.70, p=0.000, n=22$ ). The fruit detached in AZ-A abscission had lower mean values (Student $t, t=6.07, p=0.000, n=22$ ) of FDF before (68.1 $\mathrm{N})$ and after $(59.1 \mathrm{~N})$ harvesting with the canopy shaker. In both cases, the fruit detached by AZA abscission required a lower detachment force than fruit detached by AZ-C.

\section{DISCUSSION}

Abscission is a complex phenomenon, and it is difficult to predict how it occurs under real field conditions ( $\mathrm{Li}$ et al., 2017). The natural fall of mature citrus fruit is conditioned by factors that can act individually or be linked, and may be sequential or simultaneous (Iglesias et al., 2007). These factors may have a genetic or a molecular regulation basis (Merelo et al., 2017), may involve the metabolism of the plant through the availability of carbohydrates in young fruit (Iglesias et al., 2003), defoliation during a period of exponential growth (Mehouachi et al., 1995, Mehouachi et al., 2000), concentrations of abscisic acid and the release of ethylene (Iglesias et al., 2007) or be a product of the external environment, such as water deficit or biotic stress produced by pathogens (Olsson and Butenko, 2018).

When abscission is forced, new ways of detachment appear (apart from AZ-A and AZ-C) such as peel tear, caused by a mechanical break in the flavedo. This break is not very common, occurring in less than $8 \%$ of sampled fruit. However, these fruits showed a higher FDF than the rest of AZ studied. This type of detachment means that the fruit can only be destined for industrial use due to the lack of calyx and to the risk of the entrance of pathogens that may harm the fruit during storage. The percentage of fruit with peel tear may change depending on citrus type and variety, with thin-peeled fruit such as tangerines more susceptible. 
Our results show that AZ-C is the most common AZ, coinciding with Merelo et al. (2017). The snap method causes detachment in AZ-C similar to natural abscission. However, the canopy shaker performed its activity on the branches of the tree, detaching the fruit at the weakest point, both AZ-C and AZ-A. The increase in the number of breakages by AZ-A with a canopy shaker was related to lower values of FDF. A similar result was obtained for lemons (Torregrosa et al., 2010), where the FDF values with abscission in AZ-C reduced throughout the harvesting season, reaching values to equal abscission in AZ-A, which remained constant, by the end of the period. Unlike lemons, the sweet orange variety Valencia has a high FDF compared to other varieties of orange (Torregrosa et al., 2009; Peterson, 1998) which facilitates AZ-A breakage. The abscission pattern could be different in other varieties of orange, influenced by the FDF.

AZ-Abscission results in fruits that are plugged and generates the fall of leaves, branches and buds, commonly known as debris. Mechanical harvesting with a canopy shaker may increase debris production at least $20 \%$ (Roka et al., 2012), and may reach up to $250 \%$ compared to the snap method (Spann and Danyluk, 2010), which implies an extra fruit processing cost. In addition, the presence of a stem longer than $4 \mathrm{~mm}$ on fruit can cause damage to other fruit during transport. The percentage of fruit with AZ-C abscission and conserved calyx with the canopy shaker (41.6\%) was similar to the result obtained by (Torregrosa et al., 2010) with a trunk shaker (41.7\%) or with a hand-held shaker (43.3\%). Moreno et al. (2015) used a trunk shaker in varieties of mandarins and oranges and obtained low percentages of fruit without calyx, between 9.3 and $0.6 \%$, with a harvesting efficiency that ranged from 67 to $85 \%$.

Fruit detached with the pull test method showed different $A Z s$, the most frequent of which were those that required a lower FDF value; in this case, fruit detached in AZ-A, with an average value of $63.8 \mathrm{~N}$. According to Glozer (2008), the right evaluation of FDF should be performed only in AZ-C, with a higher average value $(79.3 \mathrm{~N})$. In addition, the FDF may vary depending on the way in which the method is performed (Pozo et al., 2007), decreasing as the angle to the fruit axis increases (Liu et al., 2018). Evaluation of FDF has shown a limited application to predict the efficiency of harvesting with a canopy shaker. (Savary et al., 2011) showed that the maximum value of FDF under laboratory conditions was only $18 \%$ of the traditional method of measuring FDF with the pull test. The average FDF values did not vary significantly during the season, but did show a decreasing trend. For both the canopy and the trunk shaker, a reduction in FDF improves the efficiency of the machines, requiring a less aggressive shake (Roka et al., 2005). Reducing FDF was useful to improve a harvesting efficiency of $10-12 \%$, but for values higher than $35 \%$ it was not useful (Hartmond et al., 2000).

Canopy shaker systems can achieve a high harvest efficiency (90-95\%) in the harvestable zones of the trees where a suitable contact occurs between rods and the canopy (Roka et al., 2014). The shaking process combines a forced vibration with impact on branches and fruit, depending on rod design (Pu et al., 2018), the vibration pattern of frequency and amplitude (Castro-Garcia, Sola -Guirado and Gil-Ribes 2018), and rod penetration into the tree canopy (Liu et al., 2018). The vibration generated produces a high response of fruit, stems and branches (Castro-Garcia et al., 2017). Canopy shaker system reached a higher number of fruit abscissions in AZ-C than the pull test but, lower than using the snap method. However, the fruit remaining on the tree had a lower FDF after the mechanical harvesting when they had AZ-A detachment. This effect was also described by Savary et al., (2010) who attributed the twisting and bending actions during mechanical harvesting as the main cause of fruit detachment.

\section{CONCLUSIONS}

The fruit detachment methods produce different abscission patterns. Mechanical harvesting with canopy shakers shows an abscission pattern in AZ-A higher than natural fall and manual snap method, where AZ-C predominates. Fruit detachment with the canopy shaker showed a 
lower FDF in the branch (AZ-A) than in the fruit (AZ-C), boosting the generation of debris and the fall of fruit with calyx. Fruit remaining on the tree after harvesting with the canopy shaker showed a lower FDF than before.

\section{ACKNOWLEDGMENTS}

This work has been supported by research project RTA2014-00025-C05-03 of the National Institute for Agricultural and Food Research and Technology (INIA, Spain) financed by FEDER funds.

\section{REFERENCES}

Castro-Garcia, S., G. L. Blanco-Roldán, L. Ferguson, E. J. González-Sánchez \& J. A. Gil-Ribes (2017) Frequency response of late-season 'Valencia' orange to selective harvesting by vibration for juice industry. Biosystems Engineering, 155, 77-83.

Castro-Garcia, S., R. R. Sola-Guirado \& J. A. Gil-Ribes (2018) Vibration analysis of the fruit detachment process in late-season 'Valencia' orange with canopy shaker technology. Biosystems Engineering, 170, 130-137.

Glozer, K. (2008) Fruit Removal Force (FRF, Pull Force): Why and How Measure it. Fruit and Nut Research and Information Center. University of California.

Goren, R. (1993) Anatomical, physiological, and hormonal aspects of abscission in citrus. Horticultural Reviews, 15, 145-182.

Hartmond, U., J. D. Whitney, J. K. Burns \& W. J. Kender (2000) Seasonal variation in the response of 'Valencia' orange to two abscission compounds. HortScience, 35, 226-229.

Iglesias, D. J., M. Cercós, J. M. Colmenero-Flores, M. A. Naranjo, G. Ríos, E. Carrera, O. RuizRivero, I. Lliso, R. Morillon, F. R. Tadeo \& M. Talon (2007) Physiology of citrus fruiting. Brazilian Journal of Plant Physiology, 19, 333-362.

Iglesias, D. J., F. R. Tadeo, E. Primo-Millo \& M. Talón (2003) Fruit set dependence on carbohydrate availability in citrus tress. Tree physiology, 23, 199-204.

Ladaniya, M. S. (2008) 8 - HARVESTING, Citrus Fruit. Academic Press.

Li, X., A. Kitajima, K. Kataoka, R. Takisawa \& T. Nakazaki (2017) Anatomical Observations of the Citrus Fruit Abscission Zone and Morphological Changes of the Cells during Secondary Physiological Fruit Drop. The Horticulture Journal, advpub.

Liu, T. H., R. Ehsani, A. Toudeshki, X. J. Zou \& H. J. Wang (2017) Experimental Study of Vibrational Acceleration Spread and Comparison Using Three Citrus Canopy Shaker Shaking Tines. Shock and Vibration, 2017.

Liu, T. H., G. Luo, R. Ehsani, A. Toudeshki, X. J. Zou \& H. J. Wang (2018) Simulation study on the effects of tine-shaking frequency and penetrating depth on fruit detachment for citrus canopy-shaker harvesting. Computers and Electronics in Agriculture, 148, 54-62.

Mehouachi, J., D. J. Iglesias, F. R. Tadeo, M. Agustí, E. Primo-Millo \& M. Talon (2000) The role of leaves in citrus fruitlet abscission: effects on endogenous gibberellin levels and carbohydrate content. Journal of Horticultural Science and Biotechnology, 75, 79-85.

Mehouachi, J., D. Serna, S. Zaragoza, M. Agusti, M. Talon \& E. Primo-Millo (1995) Defoliation increases fruit abscission and reduces carbohydrate levels in developing fruits and woody tissues of Citrus unshiu. Plant Science, 107, 189-197. 
Merelo, P., J. Agustí, V. Arbona, M. L. Costa, L. H. Estornell, A. Gómez-Cadenas, S. Coimbra, M. D. Gómez, M. A. Pérez-Amador, C. Domingo, M. Talón \& F. R. Tadeo (2017) Cell wall remodeling in abscission zone cells during ethylene-promoted fruit abscission in citrus. Frontiers in Plant Science, 8.

Moreno, R., A. Torregrosa, E. Moltó \& P. Chueca (2015) Effect of harvesting with a trunk shaker and an abscission chemical on fruit detachment and defoliation of citrus grown under Mediterranean conditions. Spanish Journal of Agricultural Research, 13.

Olsson, V. \& M. A. Butenko (2018) Abscission in plants. Current Biology, 28, R338-R339.

Peterson, D. L. (1998) Mechanical harvester for process oranges. Applied Engineering in Agriculture, 14, 455-458.

Pozo, L., A. Malladi, K.-J. John-Karuppiah, Y. Lluch, F. Alferez \& J. K. Burns (2007) Daily Fluctuation in Fruit Detachment Force of 'Valencia' Orange Is related to Time of Day, Temperature, Relative Humidity, Fruit Weight, and Juice Percentage. Proceedings of the Florida State Horticultural Society, 120, 41-44.

Pu, Y., A. Toudeshki, R. Ehsani, F. Yang \& J. Abdulridha (2018) Selection and experimental evaluation of shaking rods of canopy shaker to reduce tree damage for citrus mechanical harvesting. International Journal of Agricultural and Biological Engineering, 11, 48-54.

Roka, F. M., J. K. Burns \& R. S. Buker (2005) Mechanical harvesting without abscission agentsYield impacts on late season 'Valencia' oranges. Proc. Fla. State Hort. Soc, 118, 25-27.

Roka, F. M., R. J. Ehsani, S. H. Futch \& B. R. Hyman (2014) Citrus mechanical harvesting systems - Continuous canopy shakers.

Roka, F. M., R. J. Ehsani \& T. Spann (2012) Harvest debris and cost implications for mechanical harvesting. In Acta Horticulturae, ed. J. P. Syvertsen, 159-160.

Savary, S. K. J. U., R. Ehsani, M. Salyani, M. A. Hebel \& G. C. Bora (2011) Study of force distribution in the citrus tree canopy during harvest using a continuous canopy shaker. Computers and Electronics in Agriculture, 76, 51-58.

Savary, S. K. J. U., R. Ehsani, J. K. Schueller \& B. P. Rajaraman (2010) Simulation study of citrus tree canopy motion during harvesting using a canopy shaker. Transactions of the ASABE, $53,1373-1381$.

Spann, T. M. \& M. D. Danyluk (2010) Mechanical harvesting increases leaf and stem debris in loads of mechanically harvested citrus fruit. HortScience, 45, 1297-1300.

Torregrosa, A., E. Ortí, B. Martín, J. Gil \& C. Ortiz (2009) Mechanical harvesting of oranges and mandarins in Spain. Biosystems Engineering, 104, 18-24.

Torregrosa, A., I. Porras \& B. Martín (2010) Mechanical harvesting of lemons (cv. Fino) in Spain using abscission agents. Transactions of the ASABE, 53, 703-708. 
Table 1. Characteristics of tested citrus orchards.

\begin{tabular}{lcccccccc}
\hline & \multicolumn{7}{c}{ Harvesting season } \\
\hline & \multicolumn{7}{c}{ May 2017 } & \multicolumn{5}{c}{ May-June 2018 } \\
\hline Date & $9^{\text {th }}$ & $16^{\text {th }}$ & $23^{\text {rd }}$ & $31^{\text {st }}$ & $8^{\text {th }}$ & $16^{\text {th }}$ & $23^{\text {rd }}$ & $1^{\text {st }}$ \\
\hline Plot tested & 1 & 2 & 3 & 3 & 3 & 4 & 4 & 5 \\
\hline Date planted & 2007 & 2006 & 2005 & 2005 & 2005 & 2006 & 2006 & 2006 \\
& & & & & & & & \\
\hline Plot area (ha) & 33.1 & 54.7 & 38.0 & 38.0 & 38.0 & 57.3 & 57.3 & 29.0 \\
\hline $\begin{array}{l}\text { Distance between } \\
\text { rows (m) }\end{array}$ & 7.0 & 7.0 & 7.0 & 7.0 & 7.0 & 7.5 & 7.5 & 7.0 \\
\hline $\begin{array}{l}\text { Tree distance in } \\
\text { same row (m) }\end{array}$ & 3.0 & 3.0 & 3.8 & 3.0 & 3.8 & 3.0 & 3.0 & 3.0 \\
\hline Hedge height $(\mathrm{m})$ & 3.8 & 3.5 & 4.3 & 4.2 & 3.5 & 3.4 & 3.9 & 3.6 \\
\hline Hedge width (m) & 3.7 & 3.7 & 4.2 & 4.5 & 3.7 & 4.0 & 3.4 & 3.6 \\
\hline
\end{tabular}




\section{Figures}

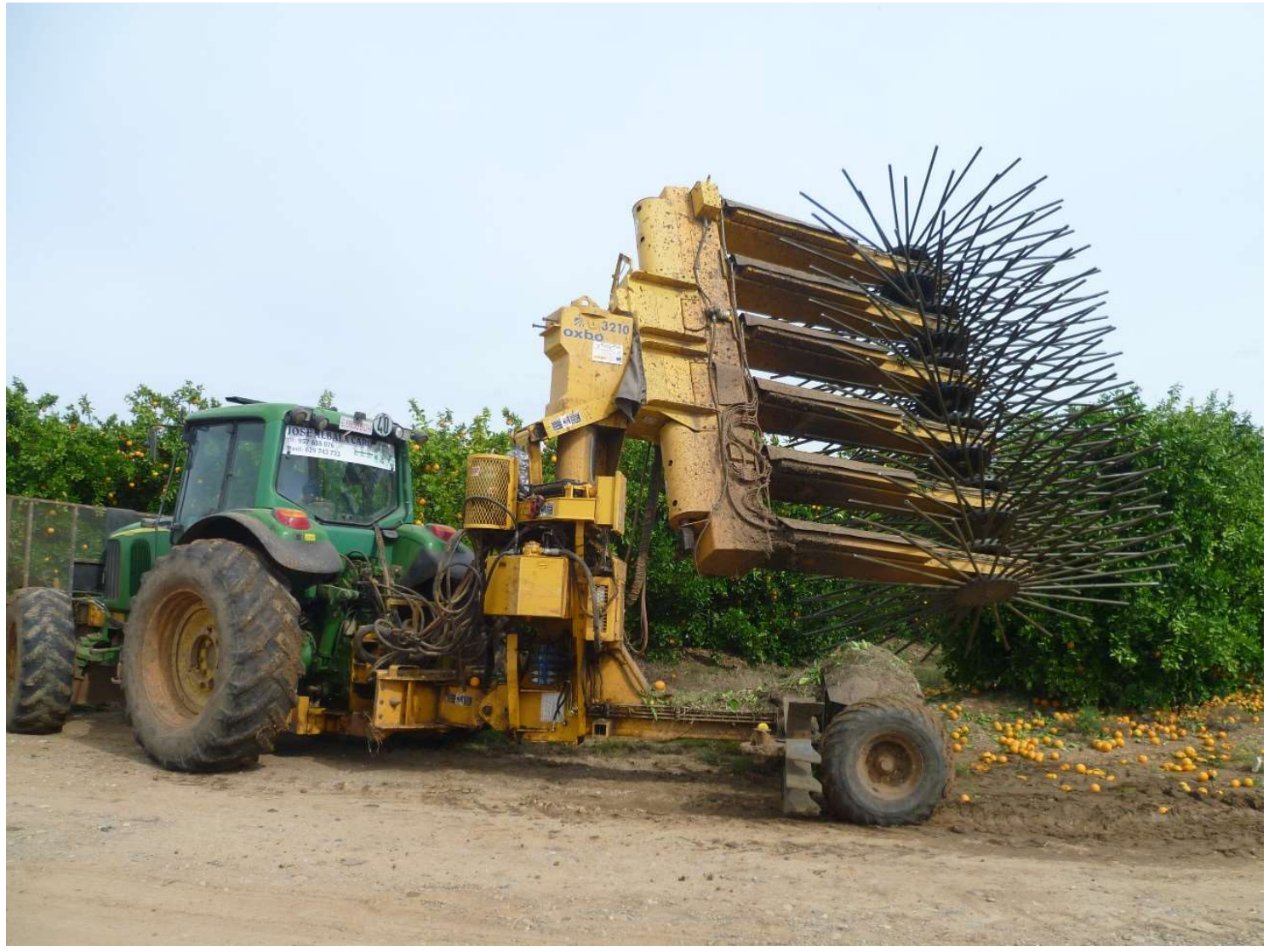

Figure 1. Mechanical citrus harvesting with a tractor-drawn continuous canopy shaker system (Oxbo, 3210).

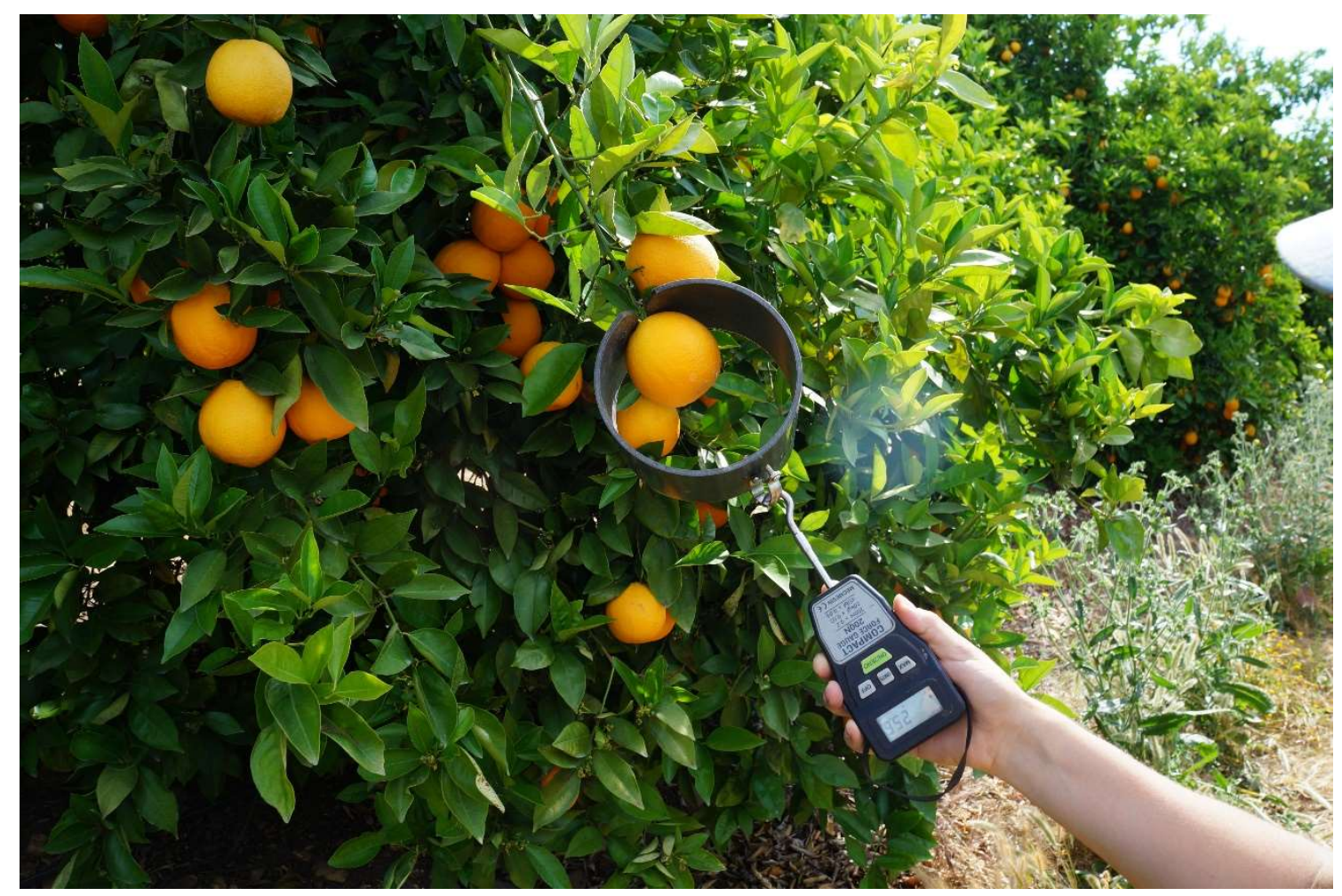

Figure 2. Measurement of citrus fruit detachment force with a pull test. 


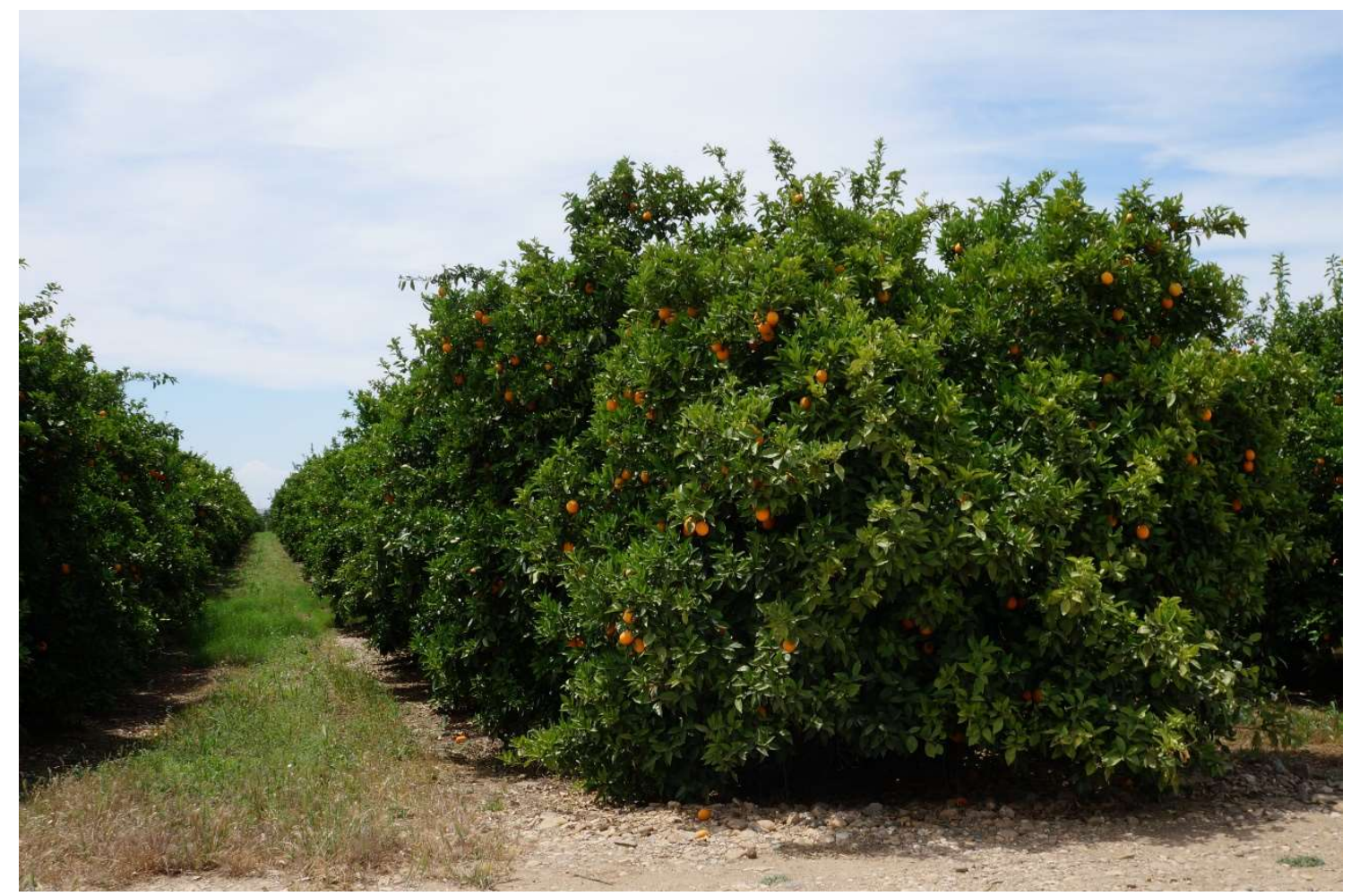

Figure 3. Sweet orange orchard in hedgerow for mechanical harvesting with a canopy shaker

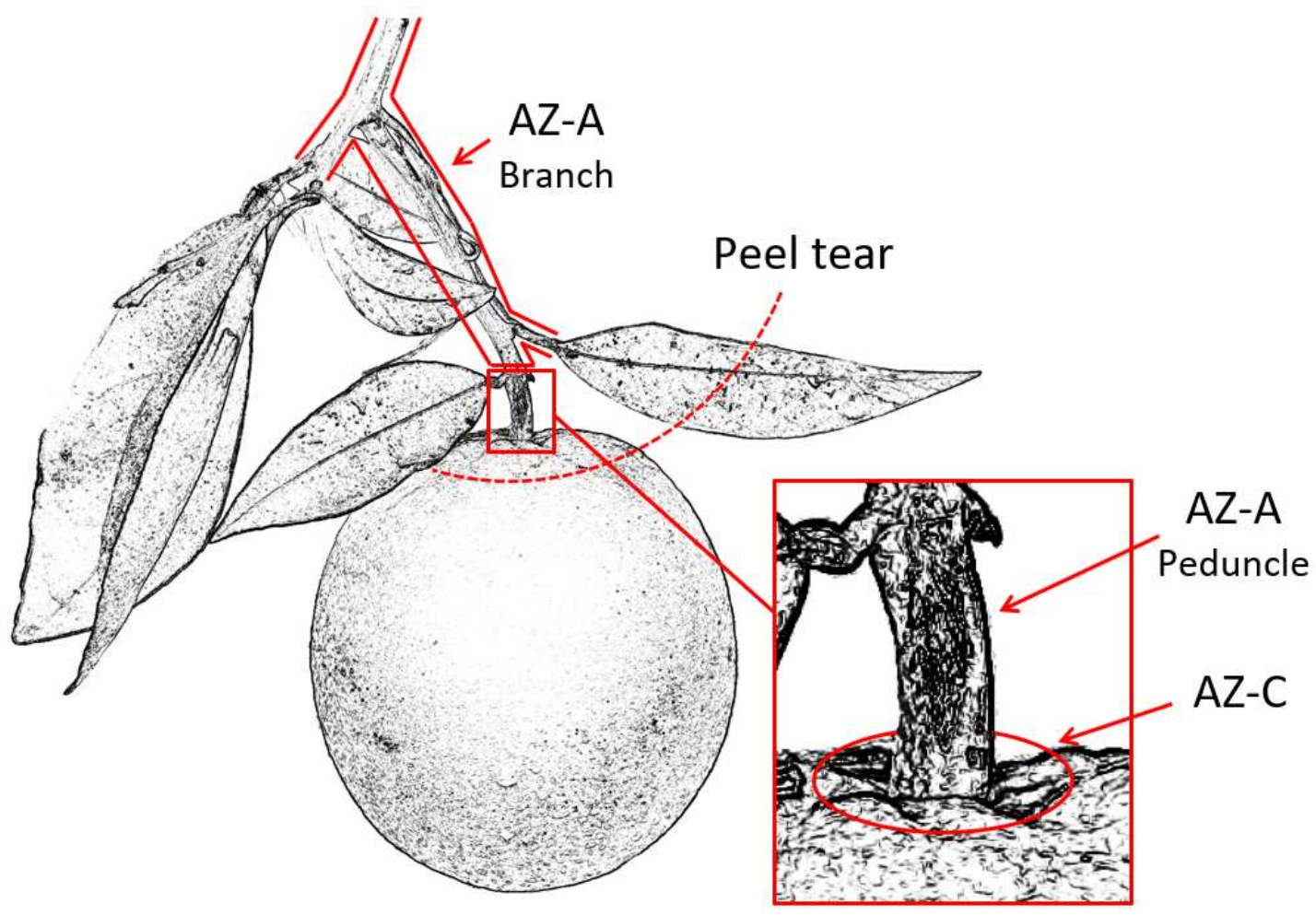

Figure 4. Scheme of citrus fruit abscission zones (AZ) under different detachment methods. 


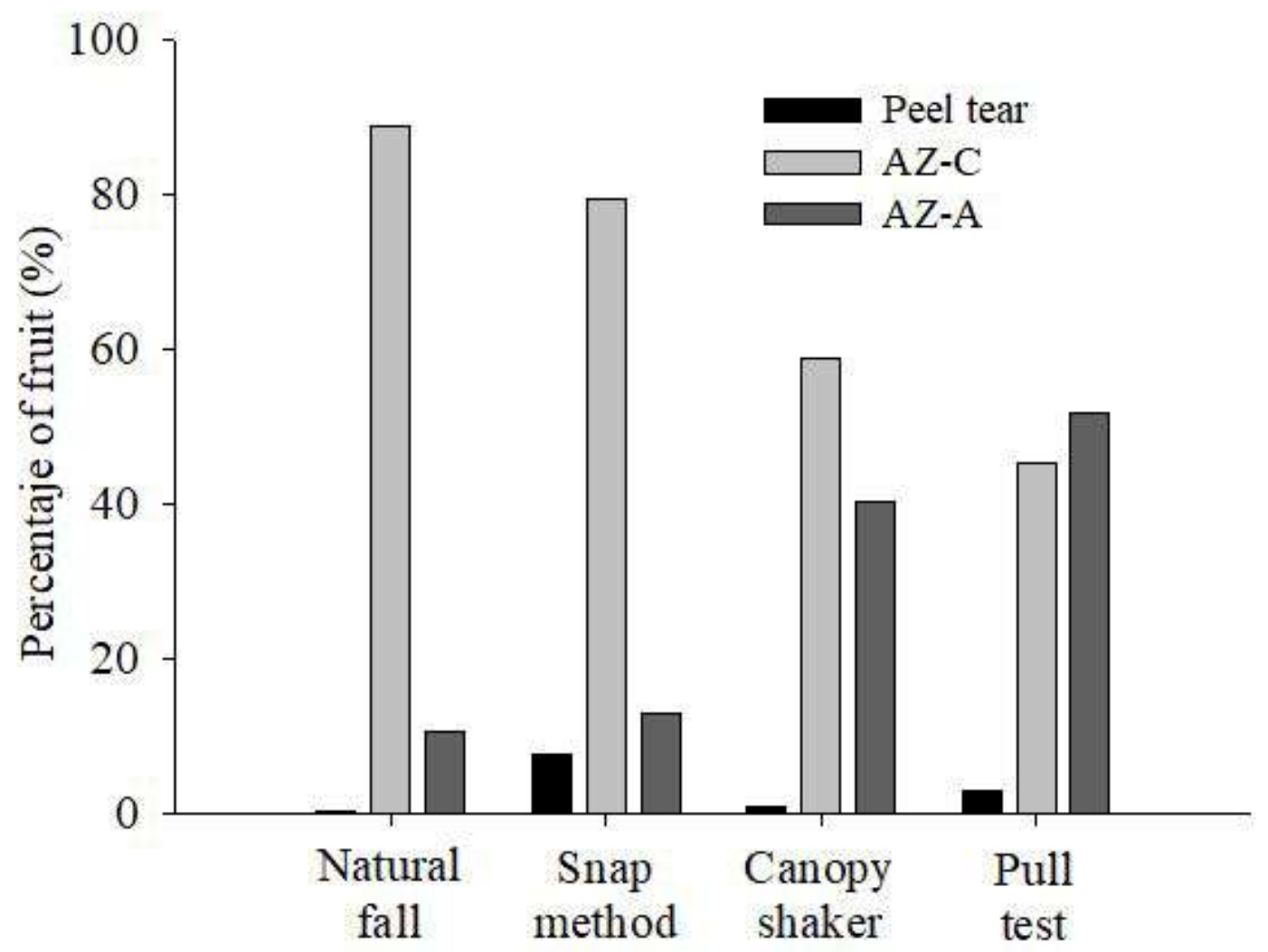

Figure 5. Fruit abscission pattern according to abscission zones (AZ) and detachment methods.

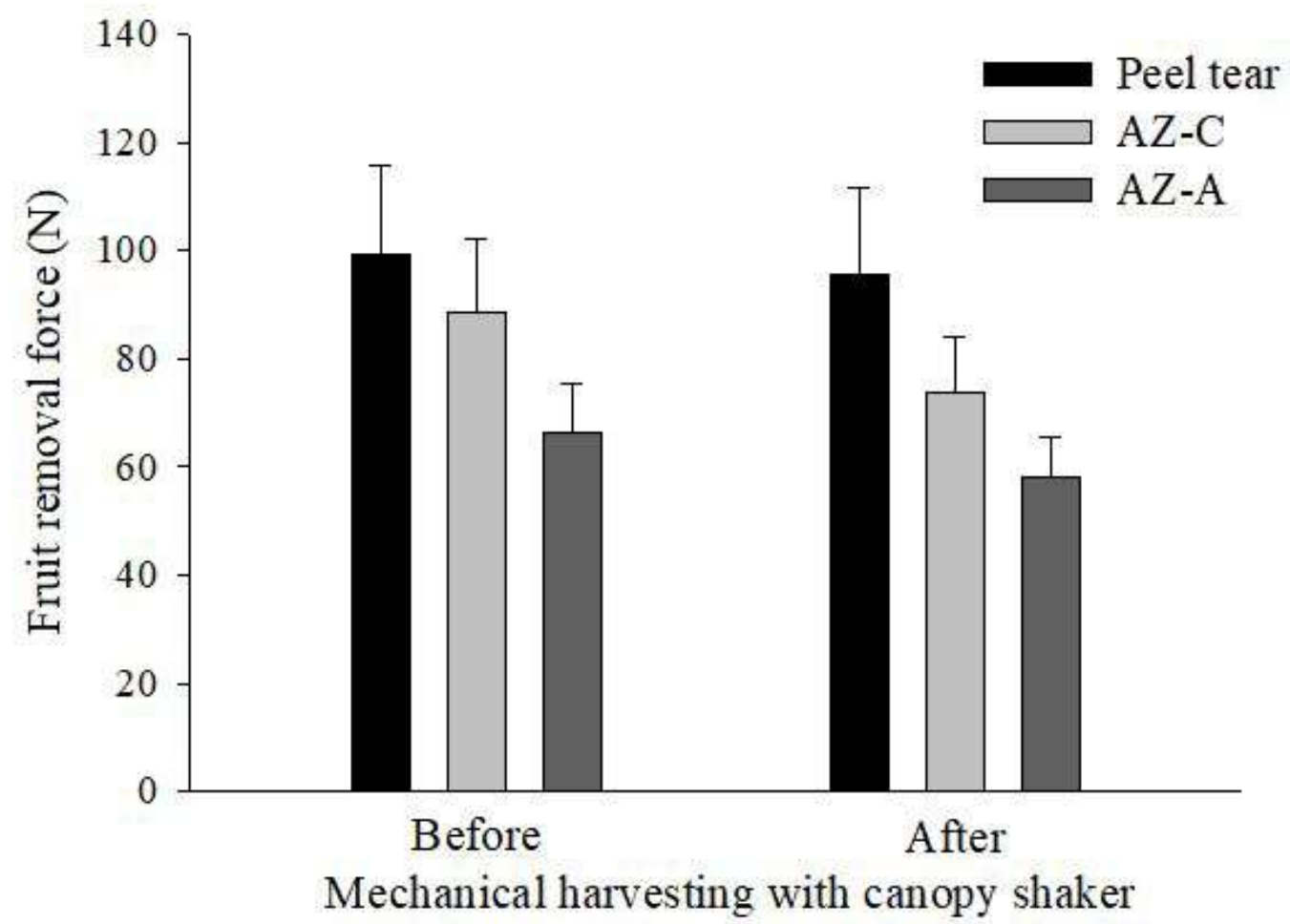

Figure 6. Removal force required to detach fruit in the tree canopy before and after mechanical harvesting with canopy shaker according to fruit abscission zone (AZ). 